\title{
"Oldies but Goodies": Providing Background to ICMI Mission and Activities from an Archival Perspective
}

\author{
Guillermo P. Curbera, Bernard R. Hodgson and Birgit Seeliger
}

\section{Aim of the workshop}

To draw attention to the importance and usefulness of archiving among the mathematics and mathematics education communities, present some of today's modern technical tools and focus on the particular case of the ICMI Archive - a subset of the Archive of the International Mathematical Union (IMU).

1. The IMU Archive: Past and present. Why is archiving necessary? Keeping the memory of the past is a joint social responsibility. Archiving is thus a way of honouring the efforts of our predecessors. Science is not excluded from this responsibility; institutions are responsible even to a larger extent. Mathematics and mathematics education will benefit from having an accurate image of their past.

The IMU/ICMI Archive keeps records from 1950 on (the previous ones were lost). They were first stored at the Eidgenössische Technische Hochschule in Zurich. In the 1990s they were transferred to Helsinki, where Olli Lehto, former IMU Secretary, organized them. Currently they are at the permanent IMU office in Berlin. There are Regulations for the Archive, which include restrictions for certain materials (70 years for matters related to awards and prizes).

2. Technical aspects of archiving today. The IMU/ICMI Archive holds analogue and digital records. The criteria for professional archiving are authenticity, reliability, integrity, and usability of the material. Digital records cause new challenges, as they are in constant technological change. Therefore, their life

G.P. Curbera $(\bowtie)$

Universidad de Sevilla, Sevilla, Spain

e-mail: curbera@us.es 
cycle management requires long-term preservation storage and formats that may derivate from original formats to ensure the survival of their content. Special procedures for email archiving include a structured file migration into the established long-term format PDF/A, which guarantees record-keeping as well as search functions.

Images play an important role for the mathematical community. Hence the first online project of the IMU/ICMI Archive is a platform for photos. "The IMU Media Platform is offered by the IMU to help showcase and illustrate the history and activity of the Union and its commissions and associated persons or events, which supports the idea of the worldwide network of mathematicians. The IMU provides the platform so that platform members can install their own image objects in a database and offer these images to other members for their use." (Quoted from IMU website)

3. The content of the ICMI archive. Existing as a subset of the IMU Archive, the ICMI Archive comprises in particular five boxes of paper documents (mainly letters) collected during the last half of the 20th century. A large portion of these goes back to the early days of the Archive. Fewer documents have been filed since the early 1990s, when email was becoming the main channel of communication. The archived documents are mostly in English, with a few in French, German, or Italian. Of notable interest are, for instance, documents related to moments of turbulence in the life of the ICMI. The Archive also contains books produced in the context of ICMI activities (ICME proceedings, ICMI Study volumes, etc.).

Open Access Except where otherwise noted, this chapter is licensed under a Creative Commons Attribution 4.0 International License. To view a copy of this license, visit http://creativecommons. org/licenses/by/4.0/.

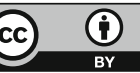

